\title{
Corporate Entrepreneurship At GE And Intel
}

John Zimmerman, Zayed University, U.A.E.

\begin{abstract}
This is the first of three planned articles concerning Corporate Entrepreneurship (CE). The author is a former entrepreneur practitioner who secured an earned doctorate from Pepperdine University in 2008, and who now teaches at Zayed University in the United Arab Emirates. In this article the author explores the concept of Corporate Entrepreneurship (CE) using case study methodology to connect previous scholarly research with data collected from successful companies. The paper discusses the problem of sustaining CE as organizations mature using Hayek's Theory of Cultural Evolution as a framework. The author suggests that corporate entrepreneurship, often called intrapreneurship, while critical for sustaining competitiveness and increasing stakeholder value, often poses a dilemma for large organizations. The different processes and strategies these companies use to attempt to sustain CE are outlined together with suggestions for integrating corporate entrepreneurship into any organization's culture, strategy, and management process. Finally, recommendations are provided as to how organizational leaders can successfully integrate corporate entrepreneurship into any organization's strategy and management systems.
\end{abstract}

Keywords: General Electric, GE, Intel, Corporate Entrepreneurship, Hayek

\section{INTRODUCTION}

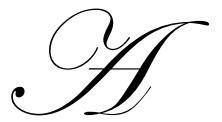

$t$ their inception, all organizations must have engaged in some form of entrepreneurship, otherwise they would not exist. The irony is that as new ventures progress from formation to become larger entities, they often implement policies, procedures, and rules that result in bureaucratic structures that, while needed to control and manage growth, often impede the innovation and creativity vital to maintain the competitive advantage initially created by entrepreneurial activity (Ireland, Kurato, \& Morris, 2006). Kenney and Mujtaba (2007) rightly connect this phenomenon to Hayek's Theory of Cultural Evolution. Hayek contends that as civilization advances from small, confined groups to more complex societies, rules and structure are spontaneously created to facilitate the complexities associated with this growth. Hayek maintained that the contradiction of this phenomenon is that this bureaucracy eventually stifles evolutionary progression, leading to the society's failure. This process is analogous to the evolution we can observe in some businesses.

For any organization to sustain success it must engage in some form of entrepreneurial activity in order to continue to effectively compete in the marketplace and continue to increase stakeholder value. Therein lies the dilemma of Corporate Entrepreneurship (CE), how can growing organizations nurture an environment for entrepreneurial activity, given that such organizations must have a certain level of policies, procedures, and processes in order to manage and control their activities. This paper attempts to compare and contrast the CE practices of two successful corporations, General Electric Company and Intel Corporation in order to understand their $\mathrm{CE}$ approach and its implications for dealing with the CE dilemma.

First let us define some terms. The term entrepreneurship has been employed for well over 200 years, yet there seems to be no single accepted scholarly definition of the phenomenon. For the purpose of this work we have selected one definition that appears to capture its essence. Entrepreneurship is "the process of creating value by bringing together a unique combination of resources to exploit an opportunity" (Stevenson \& Jarillo-Mossi, 1986, p. 10). It is helpful to deconstruct this definition into four elements. Entrepreneurship is a process consisting of stages. 
Second, entrepreneurial activity has the goal of creating value. Third, entrepreneurship involves assembling resources needed to create value in some unique fashion. Finally, entrepreneurship entails the identification or creation of an opportunity. We can see that entrepreneurship is a creative process, both in the developing the opportunity and in assembling the people, capital, technology, and other resources necessary to exploit that opportunity.

CE is a phrase used to describe entrepreneurship occurring in a mid to large sized organization (Morris, Kurako, \& Covin, 2008). Wolcott and Lippitz (2007) define CE as "the process by which teams within an established company conceive, foster, launch, and manage a new business that is distinct from the parent company but leverage's the parent's assets, market position, capabilities or other resources" (p. 75). CE embodies a kind of organizational renewal involving innovation and venturing, resulting in new products, processes, and technologies (Sathe, 1989). Kurako et al. (1990) propose that CE is often undertaken to solve a variety of problems such as marketplace stagnation caused by lack of innovation, perceived weakness in traditional management methods, and loss of talented and innovative employees who become frustrated with bureaucratic methods.

To summarize, Corporate Entrepreneurship consists of opportunity recognition and/or creation, formation of resources, and (hopefully) value creation (Stevenson \& Jarillo-Mossi, 1986) inside an established organization that is somewhat distinct from the parent company but that leverages and utilizes its resources (Wolcott \& Lippitz, 2007). We use the Stevenson \& Jarillo-Mossi definition of entrepreneurship, and the Wolcott \& Lippitz definition of $\mathrm{CE}$ as a structure to analyze $\mathrm{CE}$ data collected from two corporations to formulate a model of CE.

\section{METHODOLOGY - CE CASE STUDIES}

In order to examine $\mathrm{CE}$, this research examines how two companies - General Electric Company and Intel Corporation attempt to practice $\mathrm{CE}$. The researcher has over 15 years of experience with these organizations as a practitioner, and couples this practical experience with theory and scholarly research to gain insight into CE. The Corporate Entrepreneurship Climate Instrument (Hornsby, Kuratko, \& Zahra, 2002), and the Entrepreneurship Intensity Questionnaire (Miller, 1983), as adapted (Morris et al.), were used as the structure for assessing each observation. Through synthesis and analysis of first-hand observations, and through secondary research, the process used by each for CE was developed. Later, this information is analyzed through the lens of Hayek's Theory of Cultural Evolution.

\section{RESULTS - ANALYSIS OF GE AND INTEL CE}

\section{General Electric Company - Organizing and Sustaining CE}

Perhaps no other organization has a history of sustained CE than does GE, many of whose innovations we take for granted today. The carbon filament incandescent light bulb (1879), the first practical $\mathrm{x}$-ray technology (1920), the first commercial home television programming (1928), the first successful jet aircraft (1942), providing the basic technology for fiber optic communications (1981), magnetic-resonance guided therapy technology (1993) for medical diagnosis, leading edge technologies of today such as breakthroughs on holographic data storage that can allow up to 40 high definition movies to be stored on a single DVD (2007), are some of the many examples of GE's proven track record of innovation and CE. GE's commitment to $\mathrm{CE}$ can be measured by the resources deployed to innovation: a \$5 Billion annual budget for research with 2,800 employees, 1,000 of whom hold PhDs, resulting in 2,537 US patents through 2008 (General Electric Company [GE], 2009). But how does a large and complex organization like GE foster the climate and culture, and manage and govern the creative activity needed to sustain CE?

The approach deployed by GE to manage CE is largely based upon its evolving organizational design and strategic processes (Ocasio \& Joseph, 2005). Through the leadership of a series of chief executive officers from 1951 to 2000 (Cordiner, Borsch, Jones, and Welch), GE has established the Strategic Business Unit (SBU), supported by reporting and training, as fundamental organizational concept for CE. First implemented by Fred J. Borsch, this concept establishes relatively autonomous organizations that are free from most of the GE bureaucracy to pursue CE. Often, these SBUs report directly to the chief executive office to ensure visibility and attention. 
Examples of this approach can be found in the success of GE's commercial aircraft engine business, confirmed from personal observations and experience of this author. Other examples include the industrial diamond and the plastics businesses, the later providing the autonomy and freedom to innovate CEO Jack Welch attributes to his own personal success (Slater, 1999). While SBUs remained somewhat free from GE bureaucracy, they do not lack planning, strategic analysis, and oversight. A combination of strategic planning and analysis using the GE/McKinsey competitive strength and market competitiveness matrix (Ghemawat, 2002), coupled formally (under Jones), and later loosely (under Welch) with strategic reviews by the chief executive office provide a process of governance and oversight that still allowed the creativity and flexibility needed for CE to flourish. The author's personal experiences with GE's commercial aircraft engine venture provide first hand experiences that support this contention.

\section{Intel Corporation - Sustaining a Culture of Innovation}

Like GE, Intel has a storied history of innovation. As one of the first venture capital financed Silicon Valley start-up companies, Intel was founded in 1968 by Gordon Moore and Robert Noyce, financed by $\$ 10,000$ from one of the first venture capitalists, Arthur Rock who organized the remaining financing by selling $\$ 2.5 \mathrm{M}$ in convertible debentures. The first series of memory semiconductor products were introduced soon thereafter. In 1971 Intel executed its initial public offering at $\$ 23.50$ per share, raising \$6.8 million. Although Intel introduced its first successful microprocessor product, the 8080 in 1974, its success was largely driven by leadership in memory technology, as evidenced by the fact that in this time period Intel had invented almost all of the successful memory technologies. The legend of innovation in microprocessor technology and products is well known, but what may be of greater interest is how Intel developed a corporate culture and management system to recognize opportunities and to craft strategies to capitalize on planned technological advances, serendipitous events, and informal alliances.

Under the founder's leadership, and later under Andrew Grove, Intel had turned its corporate culture into a powerful strategic advantage, one that valued initiative, risk taking, and confrontation of ideas. This culture became so ingrained and effective that at times it was as least as powerful as formal strategic planning processes. This set of values included important norms such as constructive confrontation, disagree and then commit, knowledge power not position power, put common sense on a pedestal, and let chaos reign and reign in chaos. In addition to open communications, a bias toward action, and others, Intel culture helped make that company not only innovate, but also implement creative CE strategies to capitalize on that innovation (Tedlow, 2006). These creative strategies included the decisions to formally partner with IBM and later form an alliance with Microsoft, deemphasize the memory business in favor of the microprocessor business, the strategy to license the X86 architecture and then abandon that strategy after the success of the 80386, the now famous Intel Inside ${ }^{\mathrm{TM}}$ campaign, and a highly successful venture capital organization. Unlike GE, the significant element of Intel's CE process what not organizational or procedural, but rather was often characterized by a bottoms-up driven, contentious, rebellious and chaotic nature that was actually encouraged and supported by management. At the time, successful CE strategies at Intel almost seemed to be in spite of rather than because of any formal structure or process. This obviously has been successful so far, but one can question whether it is sustainable long term, lacking an effective formal CE process.

\section{DISCUSSION - THE CE DILEMMA}

Both GE and Intel are large, complex, and thriving organizations who have significant differences in their CE processes. The development of organizations can be connected to Hayek's Theory of Cultural Evolution, where he posits that as civilizations emerge and grow their members spontaneously create rules and structures in order to foster and facilitate this growth. Hayek goes on to maintain that this structure and rules ultimately suppress new evolutionary progression that once facilitated and fostered this growth (Feldmann, 2006). A parallel can be drawn for organizations, each organization has unique culture, processes, and procedures, which can often suppress and retard CE. We can see this phenomenon illustrated in the two case studies above, and other in research. Therein lies the CE dilemma for the organization - how can a growing organization sustain CE while at the same time maintaining the procedures and rules needed for control? Several techniques and suggestions may be helpful. 


\section{CE Health Audit}

As a beginning point, organizations should undertake a CE health audit. This would begin with data collection using the Entrepreneurial Intensity Instrument (EI) (Miller, 1983) and the Corporate Entrepreneurship Climate Instrument (CECI) (Hornsby et al., 2002) to conduct a comprehensive review of structures, controls, human resources management, and culture (Ireland et al., 2006).

\section{CE Development Training}

High potential individuals should receive training concerning the CE process, including an introduction to the CE, background on the company's successes and failures in CE, training on opportunity recognition/creation and creativity, commons barriers to $\mathrm{CE}$, and finally an overview of how corporate entrepreneurs can launch their initiatives at the company. This training should be conducted periodically for newly promoted individuals or new hires.

\section{Strategic Approach}

We can learn from the GE process for CE. GE has incorporated the strategic business unit (SBU) process into their strategic process. This means that at least annually, or during periodic strategy review sessions where previous initiatives are reviewed with the chief executive office, new initiatives can be brought forward and evaluated using the GE/McKinsey Matrix. Those approved can be resourced and SBUs can be established to manage the implementation process. This means at each periodic strategic review an agenda needs to be in place for corporate entrepreneurs to bring their ideas. Additionally, during the annual planning cycle a budget needs to be established to fund such initiatives.

\section{Internal Corporate Venture Capital}

The midsized organization can establish an internal corporate venture capital committee. The committee would consist of senior executives from the research and development, marketing, and finance departments; and if possible any board members who may have appropriate expertise. This group would then have power to approve and fund any initiative that would add potentially value to the company. The approved initiative would be either established as a new function inside an existing division if appropriate, but the ongoing management process would be similar to that used by the venture capital community meaning periodic committee "board meetings" would be conducted for review and evaluation.

\section{FUTURE RESEARCH}

Additional quantitative research will be conducted using the survey instruments to validate or refute these case studies. The initial work in this area will be conducted in the United Arab Emirates organizations, and with several multinational corporations. Additional qualitative research will also be conducted to add to the case study data already conducted to extend and build upon this paper. The author is particularly interested in studying the approaches used by Google and Cisco Systems, and by midsized companies who are in transition to becoming larger organizations. The two approaches can then be combined in a mixed methods study to further advance CE theory.

\section{AUTHOR INFORMATION}

Professor Zimmerman has a wide ranging combination of academic and industry background in finance and entrepreneurship, with General Electric Company, Caterpillar Corporation as senior controller, Intel Corporation as group controller, and Level One Communications as chief financial officer and vice president for administration. With Level One he was responsible for 2 public stock offerings, and was involved in the company's successful acquisition by Intel Corporation.

Dr. Zimmerman has taught accounting, finance, economics, and entrepreneurship at Pepperdine University, the University of Southern Nevada, and currently, at Zayed University in Abu Dhabi, UAE. 


\section{REFERENCES}

1. Feldmann, H. (2006). Hayek's theory of evolution: A critique of the critiques. In J. G. Backhaus (Ed.), Entrepreneurship, money and coordination (pp. 1-46). Cheltenham, LJK: Edward Elgar.

2. General Electric Company (2009, December 25). GE Global Research Center. Retrieved December 25, 2009, from http://www.ge.com/research/

3. Ghemawat, P. (2002, Spring). Competition and business strategy in historical perspective. The Business History Review, 76(1), 37-74.

4. Hornsby, J. S., Kuratko, D. F., \& Zahra, S. A. (2002). Middle managers' perception of the internal environment for corporate entrepreneurship: Assessing a measurement scale. Journal of Business Venturing, 17, 49-63.

5. Ireland, R. D., Kuratko, D. F., \& Morris, M. H. (2006). A health audit for corporate entrepreneurship (Part 1). Journal of Business Strategy, 27(1), 37-47.

6. Kenney, M., \& Mujtaba, B. G. (2007). Understanding corporate entrepreneurship and development: a practitioner view of organizational entrepreneurship. Journal of Applied Management and Entrepreneurship, 12(3), 73-88.

7. Kuratko, D. F., Montagno, R. V., \& Hornsby, J. S. (1990). Developing an intrapreneurial assessment instrument for an effective corporate entrepreneurial environment. Strategic Management Journal, 11(1), 49-58.

8. Miller, D. (1983). The correlates of entrepreneurship in three types of firms. Management Science, 29(3), 770-791.

9. Morris, M. H., Kuratko, D. F., \& Covin, J. G. (2008). Corporate entrepreneurship and innovation (2nd ed.). Mason, OH: Thomson Southwestern.

10. Ocasio, W., \& Joseph, J. (2005). An attention-based based theory of strategy formulation: Linking decision making and guided evolution in strategy processes. Advances in Strategic Management, 22, 39-61.

11. Parboteeah, K. (2000). Choice of type of corporate entrepreneurship: A process model. Academy of Entrepreneurship Journal, 6(1), 28-47.

12. Sathe, V. (1989). Fostering entrepreneurship in the large diversified firm. Organizational Dynamics, 18(2), 20-32.

13. Slater, R. (1999). Jack Welch and the GE way (1st ed.). New York, NY: McGraw-Hill.

14. Stevenson, H. H., \& Jarillo-Mossi, J. C. (1986). Preserving entrepreneurship as companies grow. Journal of Business Strategy, Summer (10), 76-89.

15. Tedlow, R. S. (2006). Andy Grove: The life and times of an American (1st ed.). New York, NY: Penguin Group.

16. Wolcott, R. C., \& Lippitz, M. J. (2007). The four models of corporate entrepreneurship. MIT Sloan Management Review, 49(1), 75-82. 


\section{NOTES}

